\title{
INVESTIGATING THE RELATIONSHIP BETWEEN DEPTH AND BREADTH OF VOCABULARY KNOWLEDGE AND LISTENING COMPREHENSION ACROSS DIFFERENT PROFICIENCY LEVELS AMONG IRANIAN EFL LEARNERS
}

\author{
SASAN BALEGHIZADEH ${ }^{1} \&$ PAYAM KHALEDIAN
}

Shahid Beheshti University (Iran)

\begin{abstract}
This study was an attempt to investigate the particular role of learners' depth and breadth of vocabulary knowledge in their listening comprehension. Moreover, it also sought to find out whether there is any difference between high and low listening proficiency groups in performance on depth and breadth dimensions of vocabulary knowledge. To this end, a total of 117 junior university students majoring in English language and literature participated in the study. In order to assess the learners' listening comprehension, the listening section of a paper-based version of the TOEFL was administered. Their depth and breadth of vocabulary knowledge were measured through performance on Word Associate Test and Vocabulary Levels Test, respectively. The results of data analysis indicated that both depth and breadth of vocabulary knowledge are determining factors in successful listening comprehension. However, it was found out that breadth or size of vocabulary knowledge provides a more significant contribution than depth to listening comprehension. Furthermore, the results of the study indicated that depth and breadth of vocabulary knowledge are not significant predictors of listening comprehension in the low listening ability group.
\end{abstract}

Key words: Vocabulary, depth of vocabulary knowledge, breadth of vocabulary knowledge, listening comprehension

\section{Introduction}

Learning a new language is not possible without having some knowledge of its lexis. Decarrico (2001) states that no matter language is the first, second, or foreign language of the learners, vocabulary learning is central to language acquisition. Traditionally, language proficiency has been conceptualized as performance in the four main language skills, i.e. speaking, reading, writing, and listening. Thus, to understand the role of vocabulary knowledge in language learning, it is reasonable to study it with regard to each of these skills. Reading, among these skills, has enjoyed the greatest attention (Qian, 2002; Rashidi \& Khosravi, 2010; Shen, 2008); however, speaking and listening have attracted less attention. One possible explanation for the paucity of research in this area is their elusive nature and difficulties in their measurement. This argument is approved by Brown (2001), who maintains that listening comprehension is compounded by factors of permanence and processing time.

\section{Depth and breadth of vocabulary and listening comprehension}

In studying the relationship between vocabulary knowledge and listening comprehension, it is important to consider which one is the precursor to the other. One possibility is to view the potential power of listening practice in building learners' vocabulary. According to Nation (2002), vocabulary acquisition is possible through focusing on the meaning focused input in which learners engage in meaningful written and spoken

\footnotetext{
1 E-mail: sasanbaleghizadeh@yahoo.com
} 
texts. Nation believes that even though relying on spoken and written input alone is leaving too much to chance and that vocabulary learning in this way is fragile, this is not intended to mean that such learning is not worthwhile. In line with this claim, Elley (1989) conducted a study in which the role of listening to short stories in vocabulary learning was investigated. As for the results of her study, she found that listening to short stories when read out aloud is a significant source of vocabulary acquisition.

Another perspective on the interrelation between vocabulary knowledge and listening comprehension is to view vocabulary knowledge as leading to better listening comprehension. This approach is best manifested in listening classes which involve a pre-listening stage in which teachers embark on a great deal of pre-teaching of unfamiliar vocabulary expected to be heard in the spoken text. Field (2002) recommends that teachers present three or four critical words prior to listening comprehension. There are also a number of studies in which researchers have rightly recognized the significant role of learning particular words before listening comprehension tests. Ching-shyang Chang (2007), for instance, compared three groups of learners with differing length of preparation time before listening comprehension and found that the more preparation time the participants had, the higher scores they achieved.

Vocabulary knowledge is no longer thought of as a one-dimensional relationship between meaning and form and includes various types of knowledge. Nation (2001) presented a framework in which knowledge of words is perceived as knowledge of form, meaning, and use. Qian (2002) offered four interrelated dimensions of vocabulary knowledge: 1) breadth of vocabulary, which refers to the number of words, of which learners have some superficial knowledge; 2 ) depth of vocabulary knowledge, which refers to a higher level of knowledge including all aspects and associations of words; 3 ) lexical organization, which is related to storage and representations of words in the mind; and 4) automaticity of receptive and productive processes through which words are accessed for receptive and productive purposes. There is a general agreement on the existence of the two main aspects of vocabulary knowledge, i.e. depth and breadth of vocabulary in almost all classifications and categorizations offered for identifying the dimensions of vocabulary knowledge.

\section{The differential role of proficiency}

Several research findings confirm that learners with different proficiency levels do not function the same across various language-based skills. According to Vandergrift (2003), more skilled listeners maintain attention or redirect it when distracted, process larger chunks, infer the unknown words from the context using the top-down approach, and use more metacognitive strategies. However, less skilled listeners are easily "thrown-off" when encountered with unknown words. They segment the spoken text on a word-byword basis and use a bottom-up approach to process a text. Another important issue is the assumption that vocabulary knowledge is one, among the few factors, which differentiates proficient listeners from nonproficient ones. Meara (1996) confirms that all other things being equal, learners with large vocabularies are more proficient in a wide range of language skills and that vocabulary skills make a significant contribution to almost all aspects of $\mathrm{L} 2$ proficiency. Working within the three-phase comprehension framework proposed by Anderson (1995), i.e., perceptual, parsing, and utilization, Goh (2000) found that low ability listeners had difficulty in the perceptual and parsing stages, which are related to word recognition and association with mental lexicon, respectively. Nevertheless, for high ability listeners the problematic stage was the utilization stage which is associated with the learners' schema. In the light of the fact that vocabulary knowledge contributes to the bottom-up processing of the text, and that the differences mentioned above can be summarized into differences in either bottom-up or top-down approaches, and that learners with a range of proficiency levels draw on these approaches differently, it can be hypothesized that there is some sort of association between learners' vocabulary knowledge and their listening comprehension across different proficiency levels.

Researchers typically have been increasingly attracted to doing research on breadth of vocabulary knowledge in spite of the fact that depth of knowledge can be equally significant in language learning. As Stahr (2008) rightly argues, it is the in-depth knowledge of the words that assists learners in accessing and activating vocabulary in their mental lexicon with higher speed and automaticity for receptive and productive purposes. In fact, while listening to a piece of spoken text, students need more than mere literal or superficial 
meaning of the words. They have to make an association - which is the key feature of in-depth vocabulary knowledge - between what they hear as a mere phonological form and its connection to other aspects of words such as collocation, orthography, synonymy, etc. This distinction between depth and breadth of vocabulary knowledge is important as it will determine which aspects of vocabulary knowledge provide a better contribution to listening comprehension.

The present research was targeted on the relationship between depth and breadth of vocabulary knowledge, as two main dimensions of vocabulary knowledge and listening comprehension. It also attempted to determine the extent to which scores on depth and breadth of vocabulary knowledge would predict learners' listening comprehension scores. Additionally, the study aimed at comparing the performances of two groups on depth and breadth vocabulary tests, as assigned to high and low listening proficiency groups. Considering these objectives, the following research questions guided the study:

1. To what extent is listening comprehension related to vocabulary knowledge dimensions of depth and breadth?

2. To what extent do depth and breadth dimensions of vocabulary knowledge contribute to performance in listening comprehension?

3. To what extent are depth and breadth of vocabulary knowledge and listening comprehension interrelated across high and low listening ability groups?

4. To what extent do depth and breadth dimensions of vocabulary knowledge contribute to performance in listening comprehension across high and low listening ability groups?

\section{Method}

\subsection{Participants}

The participants were a total of 117 university students randomly sampled from junior students majoring in English language and literature. All of the participants had already passed the first conversation course and they were in the middle of the second conversation course at the time of administering the TOEFL test. In order to divide them into two groups of high and low proficient listeners, the mean score and standard deviation from the TOEFL listening comprehension test scores were used as the criteria. For this purpose, those students whose scores were a standard deviation above the mean were considered as high proficiency students and those with one standard deviation below the mean were considered as low proficiency students. Therefore, those students whose score on listening comprehension test was a standard deviation below 33.97 (the mean score) were assigned to the low group and the rest of the students were considered as the high group (one standard deviation below the mean equals the raw score of 24 on the listening comprehension test).

\subsection{Instruments}

The instruments used for data collection are as follows:

Listening section of the TOEFL. In order to measure the participants' listening proficiency, the researchers administered the listening section of a paper-based version of the TOEFL. The listening section consists of three sub-sections including short conversations (one short conversion for each item) and longer conversions (one long conversion for four or five items), measuring students' abilities in comprehending spoken English for interpersonal, instructional, and academic purposes. Overall, the test consists of 50 items with about 35 minutes allotted time. The rationale for selecting the TOEFL test was that such tests are verified as standardized tests with acknowledged high validity and reliability, and they are quite suitable for measuring the overall proficiency of language learners. Additionally, there has been a close relationship between the measures of depth and breadth of vocabulary knowledge and TOEFL scores. For instance, Beglar and Hunt (1999) reported that scores on the Levels sections of Vocabulary Levels Test are highly correlated with TOEFL scores. 
Vocabulary Levels Test (VLT). Vocabulary Levels Test is designed based on the frequency levels of words or frequency word lists. It has been used to make inferences about the test takers' vocabulary size by measuring single meanings of content words at four frequency levels $(2000,3000,5000,10000)$ and one academic level. The test has undergone a number of validation studies thenceforth (e.g., Beglar and Hunt, 1999; Read, 1988; Schmitt, Schmitt, \& Clapham, 2001). Schmitt et al. (2001) revised and expanded two versions of Vocabulary Levels Test. They used Rasch analysis, item analysis, factor analysis, and interviews with participants to validate those versions. They found both versions of the test highly reliable (alpha 0.92 for frequency levels and 0.96 for academic level). Version 2 of the test was used to measure the size or breadth of vocabulary knowledge in the present study.

Word Associate Test (WAT). Read (1993) developed Word Associate Test (WAT) at Victoria University of Wellington to measure the receptive aspects of depth of vocabulary knowledge. The test is designed based on the concept of word association. According to Read (1993), the relationship between the stimulus word and associates were of the three types: 1 ) paradigmatic: the words are synonymous or at least similar in meaning, oftentimes with one being more general than the other (e.g., conform-comply; illuminatebrighten); 2) syntagmatic: the two words are collocates that often occur together in a sentence (e.g., navysailor; restore-health); and 3) analytic: the associates represent one aspect, or component, of the meaning of the stimulus word, and are likely to form part of its dictionary definition (e.g., cycle-series; frictionsurfaces). In this study, version 3.1 (form B) of WAT was administered. It is composed of 50 items, each of which consisting of one stimulus word followed by a group of eight words, four of which are semantically associated with the target word while the other four are distracters.

\subsection{Procedure}

As mentioned earlier, the junior students of three universities participated in the present research. They agreed to participate in the study after coordinating with their concerned English Departments. Since the presence of the same participants was necessary for all the three testing sessions, it was more likely that a number of students be absent in one of the sessions. However, after conducting the first test, they were asked to be present in all of the sessions and they were informed about the time of the next test administration. Additionally, they were asked to write the same name or code in their answer sheets for the three tests. As for the order of administration of the tests, the listening test was administered first, and then tests of depth and breadth of vocabulary were conducted in time intervals of two weeks.

\section{Results}

The collected data were analyzed using such statistical procedure as calculating mean and standard deviation of scores from WAT, VLT, and TOEFL teats, Pearson Product moment, multiple regression analysis, and an independent t-test for determining the significance of differences between participants as assigned to high and low ability learners. test.1

Table 1 presents the descriptive statistic for raw scores from WAT, VLT, and listening section of TOEFL

Table 1. Descriptive statistics of raw scores $(N=117)$

\begin{tabular}{lccccc}
\hline Variable & Mean & SD & Minimum & Maximum & MPS \\
\hline Depth & 142.5 & 31.4 & 62 & 195 & 200 \\
Breadth & 108.9 & 19.9 & 59 & 148 & 150 \\
Listening & 33.9 & 9.2 & 12 & 49 & 50 \\
\hline
\end{tabular}

Note: MPS= maximum possible score; $\mathrm{SD}=$ standard deviation 
As the descriptive results of Table 1 shows, the mean score for both vocabulary breadth and depth are fairly high, amounting to about $72 \%$ and $71 \%$ of the maximum possible score, respectively. However, the standard deviation figures indicate that the standard deviation scores for depth are larger than those of the breadth test, meaning that the depth scores show more spread from the mean compared with the breadth test. Also, the mean score for listening comprehension test is 33.9 , which amounts to about $68 \%$ of the maximum possible score for this test.

In order to answer the first research question and determine the relationship between the two dimensions of vocabulary knowledge, i.e. depth and breadth and also the relationship between these two and listening comprehension, a Pearson product-moment correlation was calculated among the scores from each test. The results are presented in Table 2.

Table 2. Pearson correlations among the variables of the study in participants as a whole

\begin{tabular}{lcc}
\hline Variable & Listening & Breadth \\
\hline Depth & $0.74^{* *}$ & $0.84^{\star *}$ \\
Breadth & $0.79^{* *}$ & -
\end{tabular}

Note. ${ }^{* *}$ means that the correlation is significant at $p<0.001$ level

As can be seen from Table 2, the students' listening comprehension performance is significantly correlated with their depth of vocabulary knowledge $(r=0.74, p<0.001)$, indicating that an in-depth knowledge of vocabulary may enable learners to do well on listening proficiency test. A larger correlation was obtained between breadth (size) of vocabulary knowledge and listening comprehension $(r=0.79, p<$ 0.001 ), implying that larger vocabulary in students' repertoire may play a vital role in comprehending spoken text as well. All in all, as far as the results of the above statistical analysis reveals, the two dimensions of vocabulary knowledge can be considered as having almost equally strong relationship with listening comprehension. As for the relationship between depth and breadth of vocabulary knowledge, the results indicate a highly significant correlation between the scores from depth and breadth of vocabulary knowledge test $(r=0.84, p<0.001)$. This suggests that these two dimensions of vocabulary knowledge are closely associated in such a way that those learners who possess a large vocabulary size are more likely to possess an in-depth knowledge of vocabularies, too.

In order to answer the second research question and determine the extent to which the independent variables of depth and breadth of vocabulary knowledge predict the performance in the dependent variable, i.e. listening comprehension, a multiple regression analysis was run. Table 3 illustrates the results of this analysis.

Table 3. The results of multiple regression analysis for variable in participants as whole

\begin{tabular}{|c|c|c|c|c|c|c|c|c|}
\hline $\begin{array}{l}\text { Predictive } \\
\text { variables }\end{array}$ & MR & $\mathrm{R}^{2}$ & $\mathrm{~F}$ & $\begin{array}{c}\text { Non-sta } \\
\text { valu } \\
B\end{array}$ & $\begin{array}{l}\text { ndard } \\
\text { SS } \\
\text { SE }\end{array}$ & $\beta$ & $\mathrm{T}$ & $P$ \\
\hline Cons & - & - & - & 5.88 & 2.82 & - & -2.08 & 0.039 \\
\hline Breadth & 0.796 & 0.63 & $\begin{array}{r}199.05^{*} \\
10752^{*}\end{array}$ & 0.26 & 0.04 & 0.57 & 5.53 & .001 \\
\hline
\end{tabular}

As indicated in Table 3, the observed $F$ value is significant (at the $P<0.001$ level). Also, the T values for depth and breadth of vocabulary knowledge indicate that the independent variables significantly predicted the dependent variable of listening comprehension. The independent variables of depth and breadth of vocabulary knowledge, taken together, account for about $65 \%$ of variance in listening comprehension of the participants as a whole. Considering the unique contribution of the two variables to predicting listening 
comprehension, it can be observed that breadth of vocabulary knowledge is a stronger predictor of listening comprehension and, standing alone, predicts $63 \%$ of listening comprehension. Depth of vocabulary knowledge adds only $2.5 \%$ to the variance already afforded by breadth.

So far the focus has been on the participants as a whole without considering any division across different proficiencies. However, as a part of the study, the performance of two language ability groups with regard to their listening comprehension performance has been investigated. As mentioned, overall 117 university students participated in the study. Out of this number, 94 students were chosen as the high group and the 23 remaining students were assigned to the low group. The criteria for selection was based on the participants' mean score and standard deviation on TOEFL listening comprehension test. In order to make sure the participants were assigned to the right groups and, therefore, to determine the validity of the classification, an independent t-test was run between two groups, the results of which are presented in Table 4.

Table 4. The results of independent t-test for proficiency classification

\begin{tabular}{lllllll}
\hline Variables & Level & $\mathrm{N}$ & \multicolumn{1}{c}{ Mean } & $\mathrm{SD}$ & $\mathrm{t}$ & $\mathrm{P}$ \\
\hline \multirow{2}{*}{ Depth } & high & 94 & 151.52 & 26.41 & & \\
& low & 23 & 106.00 & 23.19 & & \\
& high & 94 & 114.96 & 15.69 & & \\
Breadth & low & 23 & 84.43 & 16.72 & & \\
& high & 94 & 37.44 & 6.43 & & \\
\multirow{2}{*}{ Listening } & low & 23 & 19.78 & 3.46 & & 0.01 \\
\hline
\end{tabular}

Note: $\mathrm{N}=$ number of participants in each group, $\mathrm{SD}=$ standard deviation.

As indicated in Table 4, the $t$ values for students' performance on depth, breadth, and listening comprehension tests reveal a significant difference between high and low groups $(p<0.01)$. This difference can be clearly observed from the differences in the mean scores calculated for each group, separately. In all of the three variables of the study the students in the high group outperformed low ability students. Therefore, it can be confidently concluded that dividing participants into high and low was quite valid. In order to find out whether there is a significant relationship among the variables of the study in low and high proficiency groups, a Pearson product moment correlation was calculated (see Table 5 and Table 6 ).

Table 5. Pearson correlations among variables of the study in low proficiency group

\begin{tabular}{lll}
\hline Variable & Listening & Breadth \\
\hline Depth & $0.52^{*}$ & $0.77^{*}$ \\
Breadth & $0.52^{*}$ & -
\end{tabular}

Note. ${ }^{*}$ means that the correlation is significant at the $p<0.01$ level

As can be seen in Table 5, a similar significant correlation was found between both depth and breadth of vocabulary knowledge and listening comprehension in low proficiency students ( $r=0.52)$. In the same group, a highly significant relationship was also found between breadth and depth of vocabulary knowledge $(\mathrm{r}=0.77)$.

Table 6. Pearson correlations among variables of the study in high proficiency group

\begin{tabular}{llc}
\hline Variable & Listening & Breadth \\
\hline Depth & $0.59^{*}$ & $0.76^{*}$ \\
Breadth & $0.68^{*}$ & - \\
\hline
\end{tabular}

Note. ${ }^{*}$ means that the correlation is significant at the $p<0.001$ level 
As illustrated in Table 6, there was a significant correlation between depth of vocabulary knowledge and listening comprehension ( $r=0.59)$, and as well, between the breadth of vocabulary knowledge and listening comprehension $(r=0.68)$. As expected, depth and breadth of vocabulary knowledge were also significantly correlated $(r=0.76)$ in high proficiency group.

By comparison of correlation values among the variables of the study between high and low proficiency groups, it could be concluded that the value of correlation between depth of vocabulary knowledge and listening comprehension in the high group is about 0.07 , larger than the same for low proficiency group. Similarly, the correlation between breadth of vocabulary knowledge and listening comprehension in high proficiency group is 0.68 , which is about 0.16 larger than the obtained correlation between the two variables in low proficiency group. It could be understood that there is a stronger relationship among variables of the study in high proficiency group than the low proficiency group. This relationship is even stronger between size of vocabulary and listening comprehension than it is between depth of vocabulary and listening comprehension.

In order to find out the extent to which the independent variables of depth and breadth predict the performance on listening comprehension in high and low listening proficiency groups, and to see whether these predictions are significant for each variable, two multiple regression analyses were conducted. The results are presented in Table 7 and Table 8.

Table 7. The results of multiple regression analysis for variable in low proficiency group

\begin{tabular}{|c|c|c|c|c|c|c|c|c|}
\hline $\begin{array}{l}\text { Predictive } \\
\text { variables }\end{array}$ & MR & $\mathrm{R}^{2}$ & $F$ & $\begin{array}{l}\text { Non-s } \\
\text { valu } \\
\text { B }\end{array}$ & $\begin{array}{l}\text { tandard } \\
\text { SS } \\
\text { SE }\end{array}$ & $\beta$ & $\bar{T}$ & $P$ \\
\hline Cons & - & - & - & 9.95 & 3.38 & - & 2.94 & 0.039 \\
\hline Breadth & 0.523 & 0.27 & 7.90 & 0.062 & 0.06 & 0.299 & 1.02 & 0.31 \\
\hline Depth & 0.555 & 0.30 & 4.44 & 0.043 & 0.04 & 0.291 & 0.99 & 0.33 \\
\hline
\end{tabular}

The results of Table 7 illustrate that about $30 \%$ of the variance in listening comprehension in low proficiency group is predicted by independent variables of depth and breadth. However, none of these variables were significant predictors of listening comprehension as the $p$ value for both depth and breadth of vocabulary knowledge was higher than 0.05 . Consequently, no multiple regression model can be drawn from the analysis to explain the predictions. At the opposite side, the regression analysis conducted for high proficiency students, however, reveals that the observed $F$ value is significant at $p<0.001$ and about $47 \%$ of listening comprehension variance is predicted by independent variables of vocabulary depth and breadth (see Table 8).

Table 8. The results of multiple regression analysis for variable in high proficiency group

\begin{tabular}{lccccccccc}
\hline $\begin{array}{l}\text { Predictive } \\
\text { variables }\end{array}$ & MR & $\mathrm{R}^{2}$ & $\mathrm{~F}$ & \multicolumn{2}{c}{$\begin{array}{l}\text { Non-standard } \\
\text { values }\end{array}$} \\
& & & & $\mathrm{B}$ & $\beta$ & $\mathrm{T}$ & $\mathrm{P}$ \\
\hline Cons & - & - & - & 5.20 & 3.60 & - & 1.44 & 0.039 \\
\hline Breadth & 0.68 & 0.46 & 79.44 & 0.22 & 0.04 & 0.53 & 4.57 & 0.001 \\
Depth & 0.69 & 0.47 & 41.63 & 0.04 & 0.02 & 0.18 & 1.58 & 0.11 \\
\hline
\end{tabular}


As can be seen form Table 8, the $p$ value for breadth of vocabulary knowledge is 0.001 , which is way smaller than the significance level (0.05). This means that the prediction of listening comprehension variance afforded by breadth of vocabulary knowledge is quite significant. However, the obtained $p$ value for depth of vocabulary knowledge is larger than $0.05(0.11>0.05)$ and it cannot be a significant predictor of listening comprehension in high proficiency group. This means that depth of vocabulary knowledge contributes very little to successful listening comprehension.

As mentioned earlier in the study, the Vocabulary Levels Test (VLT), developed by Schmitt et al., (2001), measures learners' size of vocabulary knowledge on four vocabulary frequency levels, namely 2000, 3000, 5000,1000 , and one academic level. The data from the participants' performance on each of these frequency levels helps to take an analytic look on the role of vocabulary in optimal comprehension of spoken language. Therefore, the purpose of this descriptive analysis was twofold: first, to present a profile of students' mastery of vocabulary at each frequency level, and second to narrowly determine the approximate number of words needed for a particular level of listening comprehension.

The cutoff score for mastering each level of frequency determined by Schmitt et al. (2001) is 26 out of possible 30. Therefore, those students who scored 26 and above at each of the five frequency levels were counted as the master of that level. Figure 1 illustrates the percentage of participants who mastered each frequency level.

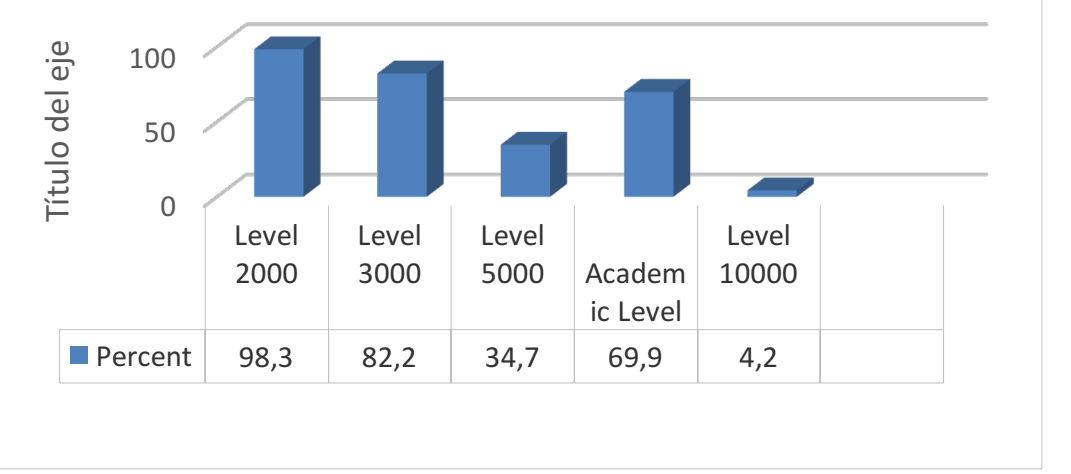

Figure 1. Percentage of students who mastered each frequency levels in the VLT

As expected, the greatest mastery percentage belongs to 2000 frequency level and the lowest percentage belongs to 10000 frequency level. This means over $98 \%$ of the participants were able to master the words at 2000 level, while only $4 \%$ of them managed to reach the mastery of words at 10000 level. The position of academic level in the diagram is a bit conspicuous. This is because of the nature of words at this level. Unlike other levels, words at the academic level are not chosen from lexical frequency lists. They are sampled from separate academic corpus called Academic Word List developed by Coxhead (2000) and words at this level range from 2000 band to the 10000 band, resulting in a varying difficulty levels.

As another part of this analysis, it was attempted to determine the gain of listening comprehension through mastering each of the frequency bands in VLT. For the reasons discussed above, it was decided to exclude academic level from the analysis. The analysis proceeded by converting the raw listening scores of participants into percentages. The next step was to identify those participants who mastered only one of the frequency bands and were not able to master the larger bands. Logically the starting point was the 2000 frequency band. After that the masters of the 3000 frequency band were detected and so forth. Following a natural trend, the participants who master a larger frequency band are expected to master the smaller bands, too. For instance, it is quite unacceptable for a participant to obtain the cutoff score for mastery of words at 5000 level without reaching the criteria at 3000 level. Then, the listening mean score of participants who mastered a particular level was calculated. The results are summarized in Figure 2. 


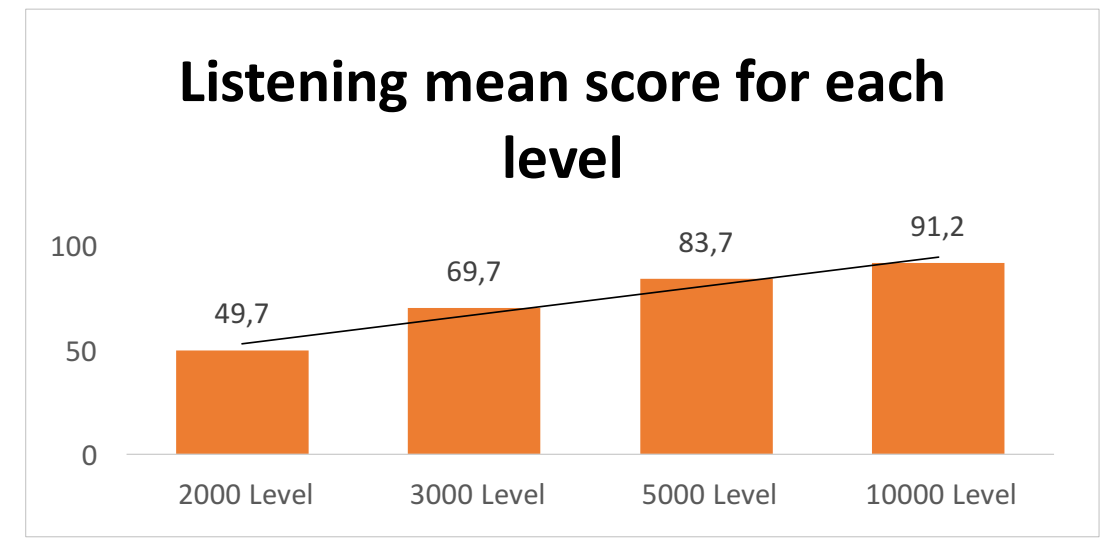

Figure 2. The degree of listening comprehension in VLT frequency levels

As can be seen from Figure 2, the degree of listening comprehension in participants who were able to master words in 2000,3000, 5000 and 10000 levels is 49.7, 69.7, 83.7, and 91.2, respectively. The results illuminate how one's listening comprehension is increased by broadening one's lexical repertoire. These incidental findings corroborate other inferential findings, confirming that there is a linear relationship between vocabulary knowledge, particularly breadth of vocabulary knowledge, and listening comprehension.

\section{Discussion}

Not surprisingly, the results accentuate the importance of vocabulary knowledge in listening comprehension. Specifically, it was found that the two major dimensions of vocabulary knowledge, i.e. depth and breadth were closely associated with listening comprehension ability. Concerning the interrelatedness of dimensions of vocabulary knowledge and listening comprehension, the results revealed positively a significant correlation in all cases. Of the independent variables of depth and breadth of vocabulary knowledge, breadth or size was found to be slightly more correlated with listening comprehension than was depth and listening comprehension. Similarly, the results of the multiple regression analysis indicated that both breadth and depth of vocabulary knowledge were significant predictors of listening comprehension. However, their prediction powers were not equal. As shown in Table 3, vocabulary breadth alone accounted for a considerable portion of variance in listening comprehension and vocabulary depth added very little to the prediction already accounted for by breadth. This suggests that vocabulary breadth is a better predictor of performance in listening comprehension.

As the results of the multiple regression analysis for high and low students indicates, despite the significant correlation, neither depth nor breadth of vocabulary knowledge were significant predictors of listening comprehension in low proficient students. In high proficient students, on the other hand, the prediction afforded by breadth was significant and, quite interestingly, it was found that depth of vocabulary knowledge was not a significant predictor of listening comprehension in the high group. In explanation, it is necessary to refer to manifold notes of and positions taken by vocabulary researchers on the relationship between breadth and depth dimensions of vocabulary knowledge. Vemeer (2001, p. 230), for instance, argues that 'deeper knowledge of words is the consequence of knowing more words, or that, conversely, the more words someone knows, the finer the network and the deeper the word knowledge'. Similarly, Milton (2009: 169) emphasizes the close affinity between depth and breadth of vocabulary knowledge and states that '... qualities of depth really seem to appear only after a sizeable vocabulary breadth has been attained'. Milton (2013) even goes further and claims that breadth and depth of vocabulary knowledge are essential components of the same dimension. Drawing on the above theoretical stances, it can be assumed that higher proficiency students have developed a larger vocabulary repertoire and, consequently, deepened their word knowledge. In this group of students, the demarcating boundaries between depth and breadth have vanished with growth in language proficiency level. Thus, as long as there is a high correlation between depth and breadth, considering these two variables separately in high proficiency students is meaningless and contribution of breadth equals to the 
contribution of depth. With regard to the differences in participants performance assigned to high and low proficiency groups, the results indicate that there is a statistically significant difference between depth and breadth scores of the two groups as being in high and low listening comprehension abilities. The learners with higher listening scores scored higher in depth and breadth of vocabulary knowledge, too and vice versa. These results confirm that learners with larger vocabulary at their disposal perform better in a range of language skills than those of poorer vocabulary knowledge. They further reveal that the deficiencies in learners' vocabulary knowledge can hinder their listening comprehension.

The results are consistent with Stahr' (2009) study in which he examined how vocabulary knowledge is associated with successful listening comprehension. He also found a significant positive correlation between depth and breadth of vocabulary and listening comprehension. However, the correlation values obtained from his study was slightly lower than those of the present research. Also, the depth and size of vocabulary knowledge as independent variables of the study had less predictive power than this study. These differences can be attributed to different listening instrument measure used in Stahr's study and, as well to the level of participants listening proficiency. Stahr administered the listening section of Cambridge Certificate of Proficiency in English (CPE) which is designed for highly proficient participants' while the participants of the current research were from a wide range of language abilities. In both studies the significant role of breadth and depth dimensions of vocabulary knowledge in listening comprehension has been emphasized; however, there is a special place for breadth of vocabulary knowledge.

The results are also in line with a host of other studies on the role of breadth and depth dimensions of vocabulary in reading comprehension (e.g., Moinzadeh \& Moslehpour, 2012; Qian, 1999; Rashidi \& Khosravi, 2010). Additionally, lexical inferencing success which is an important process in receptive skills of listening and reading (Parel, 2004), was found to be closely associated with performance on these two aspects of vocabulary knowledge (e.g. Hatami \& Tavakoli, 2013; Nassaji, 2004). The results of the above studies suggest that vocabulary knowledge is an important factor in receptive skills of listening and reading. However, it seems that there is a stronger relationship between vocabulary and reading than listening (Mecartty, 2000; Stahr, 2008). Stahr (2008), for instance, examined the relationship between vocabulary size and skills of listening, reading, and writing and found that the correlation of vocabulary size with all the three language skills was significant. However, stronger relationship was observed between vocabulary size and reading. A similar phenomenon is also evident in a study by Mecartty (2000) where she investigated the relationship between lexical and grammatical knowledge on the one hand and reading and listening on the other. Results of her study revealed that lexical knowledge was the only significant predictor of both reading and listening performance, although this 'knowledge source' appeared to be more crucial for reading than it was for listening.

There are good reasons to justify why oral skills of listening and speaking are related differently to vocabulary knowledge than written skills of reading and writing. In explanation, it is necessary to point to two separate issues: first, the number and nature of lexis embedded in each category; second, the nature of instruments which measure these skills. As for the first issue, a reference to the range of word coverage demanded by each category is warranted. Milton (2009) compared and analyzed the word coverage required for spoken and written text using British National Corpus and found out that written text is lexically more sophisticated than spoken text. This means that, by nature, a written skill such as reading demands more vocabulary range than an oral skill such as listening. Therefore, it displays more reliance on vocabulary. In discussing the second issue, it can be argued that since the vocabulary tests are invariably written based, the orthographic aspects of words are usually tapped into rather than their phonological features. Therefore, even if words are recognized orthographically, their phonological recognition may still be problematic. Not surprisingly, such tests correlate more strongly with written skills than oral ones. However, the receptive versions of vocabulary tests have been used in this study which are valid and unanimously agreed upon tests of vocabulary and are closest to what we think of as standardized test, at the absence of suitable phonological vocabulary tests.

An interesting part of the results of this research is the step by step increase of listening comprehension in accordance with participants' mastery of each frequency bands in Vocabulary Levels Test. As indicated in Figure 2, this linear relationship clearly corroborates other findings regarding the relationship between vocabulary knowledge and listening comprehension. These results contribute to lexical threshold theories for performance in language skills. Drawing on the data obtained from British National Corpus, Nation (2006) concluded that in case of $98 \%$ of coverage, about $8000-9000$ word families are required for reading 
comprehension and about 6000-7000 word families are needed for listening comprehension. Similarly, Stahr's (2009) study indicated that for advanced listeners a vocabulary size of 5000 word families, as matched with 5000 frequency band in Vocabulary Levels Test, will be required. In a similar vein, in the present research average comprehension increased from $49 \%$ at 2000 vocabulary level to $91 \%$ at 10000 vocabulary level. Also those participants who mastered 5000 vocabulary level reached about average $83 \%$ of listening comprehension which is reasonably an optimal level of comprehension. Thus, it can be concluded that in order to reach this point, learners may invest on increasing their vocabulary repertoire up to 5000 word families.

\section{Conclusions}

The results of the present research empirically confirmed the link between two well-known dimensions of vocabulary knowledge, i.e. depth and breadth and listening comprehension. Although it was found that both dimensions are closely associated with listening comprehension, breadth or size of vocabulary and listening comprehension displayed stronger tie with each other. Furthermore, comparison of high and low listening proficiency groups revealed a significant difference in their performances. These results calls for the recognition of critical role that vocabulary knowledge plays in listening comprehension. Extended exposure to receptive input such as extensive listening and reading can do a lot in improving learners' vocabulary size. However, this have to be coupled with a host of other activities designed for building in-depth vocabulary knowledge. Curits (2006) introduced various activities for this purpose such as semantic analysis, graphic representation, and graphic representations of the relationships that exist among the various meanings of the words, semantic mapping, semantic feature, concept anchoring, word sorts, and raising the word consciousness, etc. Less frequent words are less likely to occur in every text and they constitute a very low percentage of the words in any text; thus, they do not require focused teaching. The results, therefore, draw attentions to the fact that teaching high frequency vocabularies should be high in the agenda of each teacher and institute's course syllabus.

A note of caution is after all necessary here. The difference between high and low groups may be because of the difference in the number of participants when divided into two groups. As mentioned earlier in this chapter, the number of participants in the low groups is about one/third of participants in the high group. Thus, weak correlations and insignificant predictions in the low groups may be attributed to the smaller sample in this group. In other studies, with equal sample for different proficiency levels, the difference may disappear.

\section{References}

Anderson, J.R. (1995). Cognitive psychology and its implications ( $4^{\text {th }}$ ed.). New York: Freeman.

Beglar, D. \& Hunt, A. (1999). Revising and validating the 2000 word level and university word level vocabulary tests. Language Testing, 16(2), 131-162.

Brown, H.D. (2001). Teaching by principles: An interactive approach to language pedagogy. Addison Wesely Longman. Inc. USA.

Ching-Shyang Chang, A. (2007). The impact of vocabulary preparation on L2 listening comprehension, confidence and strategy use. System, 35(4), 534-550.

Coxhead, A. (2000). A new academic word list. TESOL quarterly, 34(2), 213-238.

Curtis, M. E. (2006). The role of vocabulary instruction in adult basic education. In J. Garner, B. Smith \& C. Mahwah (pp. 43-69). In review of adult learning and literacy: connecting research, policy and practice. $\mathrm{NJ}$ : Lawrence Erlbaum Associate.

Decarrico, J.S. (2001). Vocabulary learning and teaching. In M. Celce-Murcia (Ed.), Teaching English as a second or foreign language (pp. 285-299). Boston: Heinle \& Heinle.

Elley, W.B. (1989). Vocabulary acquisition from listening to stories. Reading Research Quarterly, 24(2), 174187. 
Field, J. (2002). The changing face of listening. In Richards, J.C. \& Renandya, W.A. (eds.) Methodology in Language Teaching: An anthology of current practice (pp. 242-247). Cambridge: Cambridge University Press.

Goh, C. (2000). A cognitive perspective on language learners' listening comprehension problems. System, 28(1), 55-75.

Hatami, S. \& Tavakoli, M. (2013). The role of depth versus breadth of vocabulary knowledge in success and ease in L2 lexical inferencing. TESL Canada Journal, 30(1), 1.

Meara, P. (1996). The dimensions of lexical competence. In G. Brown, K. Malmkjar \& J. Williams (Eds.), Performance and competence in second language acquisition (pp. 35 -53). Cambridge: Cambridge University Press.

Mecartty, F. H. (2000). Lexical and grammatical knowledge in reading and listening comprehension by foreign language learners of Spanish. Applied Language Learning, 11(2), 323-348.

Milton, J. (2009). Measuring second language vocabulary acquisition. Bristol: Multilingual Matters.

Milton, J. (2013). Measuring the contribution of vocabulary knowledge to proficiency in the four skills. L2 Vocabulary Acquisition, Knowledge and Use, 57-78.

Moinzadeh, A. \& Moslehpour, R. (2012). Depth and breadth of vocabulary knowledge: Which really matters in reading comprehension of Iranian EFL learners? Journal of Language Teaching and Research, 3(5), 1015-1026.

Nassaji, H. (2004). The relationship between depth of vocabulary knowledge and L2 learners' lexical inferencing strategy use and success. Canadian Modern Language Review/La Revue Canadienne des Langues Vivantes, 61(1), 107-135.

Nation, I.S.P. (2002). Best practice in vocabulary teaching. In J.C. Richards, \& W.A. Renandya, (Eds.) Methodology in Language Teaching: An anthology of current practice (pp. 267-275). Cambridge: Cambridge University Press.

Nation, I. S. P. (2001). Learning vocabulary in another language. Cambridge. Cambridge University Press.

Nation, I.S.P. (2006). How large a vocabulary is needed for reading and listening? Canadian Modern Language Review/La revue canadienne des langues vivantes, 63(1), 59-82.

Parel, R. (2004). The impact of lexical inferencing strategies on second language reading proficiency. Reading and Writing, 17(9), 847-873.

Qian, D.D. (1999). Assessing the roles of depth and breadth of vocabulary knowledge in reading comprehension. Canadian Modern Language Review/La revue canadienne des langues vivantes, 56(2), 282-308.

Qian, D.D. (2002). Investigating the relationship between vocabulary knowledge and academic reading performance: An assessment perspective. Language Learning, 52, 513-536.

Rashidi, N., \& Khosravi, N. (2010). Assessing the Role of depth and breadth of vocabulary knowledge in reading comprehension of Iranian EFL learners. Journal of Pan-Pacific Association of Applied Linguistics, 14 (1), 81-108.

Read, J. (1993). The development of a new measure of L2 vocabulary knowledge. Language Testing, 10(3), 355371.

Read, J. (1988). Measuring the vocabulary knowledge of second language learners. RELC Journal, 19(2), 12-25.

Schmitt, N., Schmitt, D. \& Clapham, C. (2001). Developing and exploring the behavior of two new versions of the Vocabulary Levels Test. Language Testing, 18(1), 55-89.

Shen, Z. (2008). The roles of depth and breadth of vocabulary knowledge in EFL reading performance. Asian Social Science, 4(12), 135-137. 
Stæhr, L.S. (2008). Vocabulary size and the skills of listening, reading and writing. Language Learning Journal, 36(2), 139-152.

Stæhr, L.S. (2009). Vocabulary knowledge and advanced listening comprehension in English as a foreign language. Studies in Second Language Acquisition, 31(4), 577-607.

Vandergrift, L. (2003). From prediction through reflection: guiding students: through the process of $L 2$ listening. Canadian Modern Language Review/La Revue canadienne des langues vivantes, 59(3), 425-440.

Vermeer, A. (2001). Breadth and depth of vocabulary in relation to L1/L2 acquisition and frequency of input. Applied Psycholinguistics, 22(2), 217-234.

Received: 08/03/2016

Accepted: 15/05/2016 